\title{
The Pattern of Juvenile Idiopathic Arthritis in a Single Tertiary Center in Saudi Arabia
}

\author{
Mohammad H. Al-Hemairi, ${ }^{1}$ Shatha M. Albokhari, ${ }^{2}$ and Mohammed A. Muzaffer ${ }^{2}$ \\ ${ }^{1}$ Department of General Pediatrics, Rabigh General Hospital, P.O. Box 51, Rabigh 21911, Saudi Arabia \\ ${ }^{2}$ Department of Pediatrics, Division of Pediatric Rheumatology, King Abdulaziz University Hospital, \\ P.O. Box. 80218, Jeddah 21589, Saudi Arabia
}

Correspondence should be addressed to Mohammad H. Al-Hemairi; alhemairi-m@hotmail.com

Received 31 August 2015; Revised 6 December 2015; Accepted 27 December 2015

Academic Editor: Kamyar Kalantar-Zadeh

Copyright (C) 2016 Mohammad H. Al-Hemairi et al. This is an open access article distributed under the Creative Commons Attribution License, which permits unrestricted use, distribution, and reproduction in any medium, provided the original work is properly cited.

\begin{abstract}
Introduction. Juvenile Idiopathic Arthritis (JIA) is the most common chronic arthritis in children. Our aim is to describe demographic, clinical, and laboratory characteristics and treatment of JIA patients followed up in Pediatric Rheumatology clinic in a tertiary center in Saudi Arabia. Methods. Medical records of all patients who are followed up between January 2007 and January 2015 were retrospectively reviewed. Data were collected about demographic, clinical, and laboratory features and treatment. Results. Total patients were 82 , males were 31 (37.8\%), and mean age of JIA onset was $7.1 \pm 3.6$ yr. Mean follow-up duration was $2.67 \pm 1.6$ yr. Systemic onset JIA (SoJIA) was the commonest (36.5\%), followed by polyarticular in $29.2 \%$ and oligoarticular in $28 \%$. Large and small joints are involved in 76 (92\%) and 30 (36.6\%), respectively. Main extra-articular feature was fever in 34 (41.4\%). Uveitis was diagnosed in $7(8.5 \%)$ and in $5(21.7 \%)$ of oligoarticular JIA. Anemia was found in 49 (59.7\%), high ESR in 45 (54.8\%), and leukocytosis and thrombocytosis in 33 (40.2\%). Positive ANA was found in 30 (36.5\%) mainly in oligoarticular subtype as 12 (52\%) patients (out of 23) had this positive test. 9 patients (10.9\%) required NSAIDs only, 6 patients (7.3\%) required NSAIDs and intraarticular steroids only, and 19 (23\%) required NSAIDs, methotrexate, steroids, and biologics. Conclusion. SoJIA is the most common JIA subtype in our study. A population based rather than a single center study will give more details about JIA characteristics in Saudi Arabia
\end{abstract}

\section{Introduction}

Juvenile Idiopathic Arthritis (JIA) is the most common chronic arthritis in children worldwide. It is a heterogeneous inflammatory disease and defined as arthritis persisting 6 weeks or longer with onset before the age of 16 years with no identifiable etiology.

The term Juvenile Idiopathic Arthritis has replaced the older terms Juvenile Rheumatoid Arthritis (JRA) and Juvenile Chronic Arthritis (JCA) proposed by the International League of Associations for Rheumatology (ILAR) in the late 1990s.

The ILAR classified JIA according to the pattern of the arthritis in the first 6 months after onset of the disease into 8 subtypes known as persistent oligoarticular, extended oligoarticular, polyarticular Rheumatoid Factor- (RF-) negative, polyarticular RF-positive, enthesitis-related arthritis (ERA), psoriatic arthritis, systemic, and undifferentiated arthritis. Each JIA subtype has its own diagnostic criteria (Table 1) [1].

The hallmark of JIA is joint inflammation and the presence of synovitis which causes synovial tissue thickening and accumulation of synovial fluid. This is manifested clinically as joint swelling, morning stiffness, joint pain, tenderness, and functional disability. Arthritis can occur in any joint but large joints are more commonly affected. Joint involvement can be mild and self-limiting and it can be more severe causing joint destruction, severe disability, and loss of joint function.

Extra-articular manifestations in JIA may cause significant morbidity. These include uveitis, fever, skin rash, 
TABLE 1: The ILAR classification of JIA.

\begin{tabular}{|c|c|}
\hline Systemic arthritis & $\begin{array}{l}\text { Arthritis with, or preceded by, daily fever of at least 2-week duration that is documented to be daily for at least } 3 \text { days } \\
\text { and accompanied by one or more of the following: (i) evanescent, nonfixed, erythematous rash; (ii) generalized } \\
\text { lymph node enlargement; (iii) hepatomegaly and/or splenomegaly; (iv) serositis } \\
{ }^{*} \text { Exclusion criteria: A, B, C, and D }\end{array}$ \\
\hline Oligoarthritis & $\begin{array}{l}\text { Arthritis in 1-4 joints during the first } 6 \text { months of disease. } \\
\text { Two subtypes: (i) persistent oligoarthritis affects no more than four joints throughout the disease course; } \\
\text { (ii) extended oligoarthritis affects a total of more than four joints after the first } 6 \text { months of disease } \\
{ }^{*} \text { Exclusion criteria: A, B, C, D, and E }\end{array}$ \\
\hline $\begin{array}{l}\text { Polyarthritis } \\
\text { (RF-negative) }\end{array}$ & $\begin{array}{l}\text { Arthritis affecting } 5 \text { or more joints during the first } 6 \text { months of disease: tests for RF are negative } \\
{ }^{*} \text { Exclusion criteria: A, B, C, D, and E }\end{array}$ \\
\hline $\begin{array}{l}\text { Polyarthritis } \\
\text { (RF-positive) }\end{array}$ & $\begin{array}{l}\text { Arthritis in } 5 \text { or more joints during the first } 6 \text { months of disease: tests for RF are positive } \\
{ }^{*} \text { Exclusion criteria: A, B, C, and E }\end{array}$ \\
\hline Psoriatic arthritis & $\begin{array}{l}\text { Arthritis plus psoriasis or arthritis plus at least two of the following: dactylitis, nail pitting, or onycholysis, psoriasis } \\
\text { in a first-degree relative } \\
{ }^{*} \text { Exclusion criteria: B, C, D, and E }\end{array}$ \\
\hline $\begin{array}{l}\text { Enthesitis-related } \\
\text { arthritis }\end{array}$ & $\begin{array}{l}\text { Arthritis plus enthesitis or arthritis or enthesitis, plus at least two of the following: presence of or a history of } \\
\text { sacroiliac joint tenderness and/or inflammatory lumbosacral pain, presence of HLA-B27 antigen, onset of arthritis in } \\
\text { a male over } 6 \text { years of age, acute (symptomatic) anterior uveitis, history of AS, ERA, sacroiliitis with IBD, reactive } \\
\text { arthritis, or acute anterior uveitis in a first-degree relative } \\
{ }^{*} \text { Exclusions criteria: A, D, and E }\end{array}$ \\
\hline $\begin{array}{l}\text { Undifferentiated } \\
\text { arthritis }\end{array}$ & $\begin{array}{l}\text { Arthritis that do not fulfill criteria in any of the above categories or fulfills criteria in two or more of the above } \\
\text { categories }\end{array}$ \\
\hline
\end{tabular}

hepatomegaly, splenomegaly, lymphadenopathy, and serositis. Apart from uveitis, most of these extra-articular features occur in SoJIA.

There are no diagnostic laboratory investigations for JIA but some laboratory findings can help to exclude other causes of arthritis and help in JIA classification.

Aim of JIA management is to control active symptoms and to prevent chronic complications in order to improve quality of life which requires comprehensive multidisciplinary team care including rheumatologists, rehabilitation specialists, occupational therapists, physical therapists, social workers, nurses, podiatrists, dieticians, psychologists or psychiatrists, and orthopedic surgeons.

There is no curative treatment for JIA but early and aggressive management has led to prolonged remission and improved outcome.

Various studies from different parts of the world showed differences in JIA characteristics including incidence, prevalence, age of onset, gender, and frequency of JIA subtypes [27].

These relative variabilities may be related to environmental, ethnic, and genetic background.

There is paucity of published studies describing JIA and its characteristics in Saudi Arabia and its neighboring countries. Most of these studies were hospital-based [8-14].

In this present study, we retrospectively reviewed medical records of a cohort of 82 JIA children who are followed up in Pediatric Rheumatology Department at King Abdulaziz University Hospital (KAUH); our objective is to present the main characteristics of JIA in children followed up in our center to know further about the pattern of the disease in Saudi Arabia and to compare these characteristics with those from other parts of the world.

\section{Patients and Methods}

This is an observational retrospective study carried out at Pediatric Rheumatology Department in King Abdulaziz University Hospital (KAUH), a tertiary center, Jeddah, Saudi Arabia.

Our study was approved by local ethical committee of pediatric department and by the University Research Ethics Committee.

All the medical records of the children who were diagnosed to have Juvenile Idiopathic Arthritis (arthritis in one or more joints lasting 2 weeks or more with no identifiable cause in those who are less than 16 years of age) from January 2007 to January 2015 were included.

The diagnosis of JIA was done by a pediatric rheumatologist and JIA classification was according to ILAR classification criteria (Table 1).

Only children who had duration of follow-up of 6 months or more were included in order to know more details about JIA characteristics.

Data were collected about number of patients of each JIA subtype, gender, age at disease onset, and duration of follow-up. The percentage of each JIA subtype was calculated and the age of disease onset and duration of follow-up were expressed as the mean \pm standard deviation (SD); these data are presented in Table 2 and Figure 1. 
TABLE 2: General characteristics of JIA patients.

\begin{tabular}{lccccccc}
\hline \multirow{2}{*}{ JIA subtype } & \multirow{2}{*}{ Number of cases (\%) } & \multicolumn{2}{c}{ Gender } & \multicolumn{2}{c}{ Age of onset (yr) } & \multicolumn{2}{c}{ Duration of follow-up (yr) } \\
& & Male (\%) & Female (\%) & Range & Mean (SD) & Range & Mean (SD) \\
\hline Oligoarticular & $23(28.04)$ & $10(43.47)$ & $13(56.52)$ & $1-12.3$ & $4.78 \pm 2.91$ & $0.7-8$ & $2.68 \pm 1.86$ \\
Polyarticular RF-positive & $4(4.87)$ & 0 & $4(100)$ & $10-14.5$ & $12.3 \pm 2.78$ & $0.5-5$ & $2.2 \pm 1.964$ \\
Polyarticular RF-negative & $20(24.39)$ & $6(30)$ & $14(70)$ & $2.5-12.4$ & $8.12 \pm 3.47$ & $0.6-5.8$ & $2.85 \pm 1.376$ \\
Systemic & $30(36.5)$ & $13(43.33)$ & $17(56.66)$ & $0.7-12.6$ & $7.25 \pm 3.47$ & $0.5-6.8$ & $2.37 \pm 1.61$ \\
Psoriatic & $4(4.87)$ & $1(25)$ & $3(75)$ & $4.7-12.2$ & $8.47 \pm 3.09$ & $1.3-6.6$ & $3.97 \pm 2.17$ \\
ERA $^{*}$ & $1(1.21)$ & $1(100)$ & 0 & - & - & - & 4.8 \\
\hline Total & $82(100)$ & $31(37.8)$ & $51(62.2)$ & $0.7-14.5$ & $7.11 \pm 3.65$ & $0.5-8$ & $2.67 \pm 1.68$ \\
\hline
\end{tabular}

*ERA: enthesitis-related arthritis.

TABLE 3: Main clinical manifestation of JIA patients.

\begin{tabular}{|c|c|c|c|c|c|c|c|}
\hline Clinical manifestations & $\begin{array}{l}\text { Oligoarticular } \\
\text { number }=23\end{array}$ & $\begin{array}{c}\text { Polyarticular } \\
\text { RF-negative } \\
\text { number }=20\end{array}$ & $\begin{array}{l}\text { Polyarticular } \\
\text { RF-positive } \\
\text { number }=4\end{array}$ & $\begin{array}{l}\text { Systemic onset } \\
\text { number }=30\end{array}$ & $\begin{array}{c}\text { Psoriatic } \\
\text { number }= \\
4\end{array}$ & $\begin{array}{c}\text { ERA } \\
\text { number }= \\
1\end{array}$ & $\begin{array}{c}\text { Total } \\
\text { number }= \\
82\end{array}$ \\
\hline Large joints involvement & $23(100 \%)$ & $20(100 \%)$ & $3(75)$ & $27(90)$ & $2(50)$ & $1(100)$ & $76(92.68)$ \\
\hline Small joints involvement & $4(17.39)$ & $7(35)$ & $3(75)$ & $13(43.33)$ & $3(75)$ & 0 & $30(36.6)$ \\
\hline Fever & 0 & $3(15)$ & 1 & $30(100)$ & 0 & 0 & $34(41.46)$ \\
\hline Uveitis & $5(21.7 \%)$ & $1(5)$ & 0 & $1(3.33)$ & 0 & 0 & $7(8.53)$ \\
\hline Skin rash & 0 & 0 & 0 & $13(43.33)$ & 4 & 0 & $17(20.73)$ \\
\hline Hepatosplenomegaly & 0 & 0 & 0 & $11(36.67)$ & 0 & 0 & $11(13.41)$ \\
\hline Lymphadenopathy & 0 & 0 & 0 & $9(30)$ & 0 & 0 & $9(11)$ \\
\hline
\end{tabular}

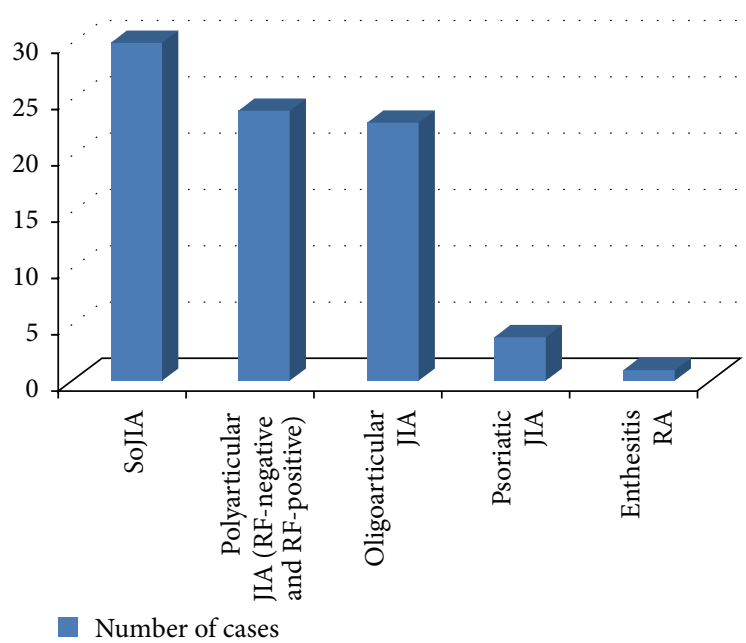

FIgURE 1: Distribution of JIA subtypes.

Main clinical data were collected about large joints involvement (knee, ankle, elbow, shoulder, and wrist) or small joints involvement and presence of uveitis during the course of the disease. The presence of fever, skin rash, hepatosplenomegaly, and lymphadenopathy at diagnosis was also recorded. These clinical findings were diagnosed by a pediatric rheumatologist while uveitis was diagnosed by ophthalmologist by slit lamp examination. These main clinical data are presented in Table 3.
Laboratory investigations were all done at KAUH laboratories.

Initial data at diagnosis included white blood cells (leukocytosis defined as WBC $>11 \times 10^{9} / \mathrm{L}$ ), hemoglobin level (anemia defined as $\mathrm{Hb}<110 \mathrm{~g} / \mathrm{L}$ ), platelets count (thrombocytosis defined as PLT $\left.>450 \times 10^{9} / \mathrm{L}\right)$, ESR $>20 \mathrm{~mm} / \mathrm{hr}$, elevated CRP $>3 \mathrm{mg} / \mathrm{L}$ and positivity of anti-nuclear antibodies (ANA), Rheumatoid Factor (RF), and HLAB27.

ANA was done by ELISA technique and ANA titre of 1:80 or more was considered positive. Positivity of ANA and RF is considered only if two samples were positive in at least three months apart. Table 4 shows the percentage of these laboratory investigation results in all JIA subtypes.

Review of anti-rheumatic pharmacologic treatments used during the study period included (nonsteroidal antiinflammatory drugs (NSAIDs), intra-articular corticosteroids (IAC) or systemic corticosteroids, methotrexate (MTX), and biologic agents) was done. Number and percentage of those who were treated with NSAIDs alone, NSAIDs and IAC, NSAIDs, IAC and MTX, NSAIDs and systemic steroids, NSAIDs and MTX, NSAIDs, MTX and systemic steroids, NSAIDs, MTX and biologics, NSAIDs, MTX, and biologics and IAC and those who had joint surgery in each JIA subtype were calculated and presented in Table 5.

Other Disease-Modifying Antirheumatic Drugs (DMARDs) like leflunomide, cyclosporine, and azathioprine were infrequently used and they were not included.

Data statistical analysis was done manually. 
TABLE 4: Main laboratory investigation.

\begin{tabular}{|c|c|c|c|c|c|c|c|c|}
\hline & $\begin{array}{c}\text { Anemia } \\
\mathrm{Hb}<110 \\
\mathrm{~g} / \mathrm{L}(\%)\end{array}$ & $\begin{array}{c}\text { Leukocytosis } \\
\text { WBC > } 11 \times \\
10^{9} / \mathrm{L}(\%)\end{array}$ & $\begin{array}{c}\text { Elevated PLT } \\
450 \times 10^{9} / \mathrm{L} \\
(\%) \\
\end{array}$ & $\begin{array}{c}\text { Elevated ESR } \\
>20 \mathrm{~mm} / \mathrm{hr} \\
(\%)\end{array}$ & $\begin{array}{l}\text { Elevated CRP } \\
>3 \mathrm{mg} / \mathrm{L}(\%)\end{array}$ & $\begin{array}{c}\text { Positive ANA } \\
(\%)\end{array}$ & Positive RF & $\begin{array}{c}\text { Positive HLA } \\
\text { B27 (\%) }\end{array}$ \\
\hline $\begin{array}{l}\text { Systemic onset } \\
(\text { number }=30)\end{array}$ & $24(80)$ & $21(70)$ & $21(70)$ & $24(85.71)$ & $22(73.33)$ & $4(13.33)$ & 0 & $\mathrm{ND}^{*}$ \\
\hline $\begin{array}{l}\begin{array}{l}\text { oligoarticular } \\
\text { (number = 23) }\end{array} \\
\end{array}$ & $9(39.13)$ & $4(17.4)$ & $3(17.64)$ & $7(30.43)$ & $5(21.74)$ & $12(52.17)$ & 0 & $\mathrm{ND}^{*}$ \\
\hline $\begin{array}{l}\text { Polyarticular } \\
\text { RF-negative } \\
(\text { number }=20)\end{array}$ & $12(60)$ & $6(30)$ & $7(35)$ & $10(50)$ & $4(25)$ & $9(45)$ & 0 & $\mathrm{ND}^{*}$ \\
\hline $\begin{array}{l}\text { Polyarticular } \\
\text { RF-positive } \\
(\text { number }=4)\end{array}$ & $3(75)$ & $1(25)$ & $1(25)$ & $2(50)$ & $1(25)$ & $2(520)$ & $4(100)$ & $\mathrm{ND}^{*}$ \\
\hline $\begin{array}{l}\text { Enthesitis } \\
\text { related (number } \\
=1 \text { ) }\end{array}$ & 0 & 0 & 0 & $1(100)$ & $1(100)$ & 0 & 0 & $1(100)$ \\
\hline $\begin{array}{l}\text { Psoriatic } \\
(\text { number }=4)\end{array}$ & $1(25)$ & $1(25)$ & $1(25)$ & $1(25)$ & 0 & $1(25)$ & 0 & $\mathrm{ND}^{*}$ \\
\hline $\begin{array}{l}\text { Total (number }= \\
82)\end{array}$ & $49(59.75)$ & $33(40.24)$ & $31(37.8)$ & $45(54.87)$ & $33(40.24)$ & $30(36.58)$ & $4(4.87)$ & $1(1.2)$ \\
\hline
\end{tabular}

${ }^{*} \mathrm{ND}$ : not done.

TABLE 5: Pharmacologic therapy used in JIA patients.

\begin{tabular}{|c|c|c|c|c|c|c|c|}
\hline & $\begin{array}{c}\text { Oligo. } \\
\text { JIA = } 23\end{array}$ & Poly. RF-neg. $=20$ & Poly. RF-Pos. $=4$ & SoJIA $=30$ & $\mathrm{ERA}=1$ & Psoriatic $=4$ & Total $=82(\%)$ \\
\hline NSAIDs alone & 6 & 2 & 0 & 0 & 1 & 0 & $9(10.97)$ \\
\hline NSAIDs, AC & 4 & 2 & 0 & 0 & 0 & 0 & $6(7.31)$ \\
\hline NSAIDs, IAC, MTX & 3 & 0 & 1 & 0 & 0 & 0 & $4(4.87)$ \\
\hline NSAIDs, steroids & 1 & 0 & 0 & 5 & 0 & 0 & $6(7.31)$ \\
\hline NSAIDs, MTX & 5 & 0 & 1 & 3 & 0 & 3 & $12(14.63)$ \\
\hline NSAIDs, MTX, steroids & 0 & 6 & 0 & 7 & 0 & 1 & $14(17)$ \\
\hline NSAIDs, MTX, biologics & 1 & 5 & 1 & 1 & 0 & 0 & $8(9.75)$ \\
\hline NSAIDs, MTX, biologics, steroids & 2 & 4 & 0 & 13 & 0 & 0 & $19(23.17)$ \\
\hline NSAIADs, MTX, biologics, IAC & 1 & 1 & 1 & 1 & 0 & 0 & $4(4.87)$ \\
\hline Joint surgery & 1 & 1 & 1 & 0 & 0 & 0 & $3(3.65)$ \\
\hline
\end{tabular}

NSAIDs: Nonsteroidal anti-inflammatory drugs, IAC: intra-articular corticosteroids, and MTX: methotrexate.

\section{Results}

Total patients reviewed in this study were $85 ; 3$ patients were excluded because of insufficient data due to irregular followup (2 oligoarticular JIA, 1 polyarticular JIA).

Table 2 shows general characteristics of the patients: systemic onset JIA was the most common JIA subtype $36.5 \%$ (30 patients) followed by polyarticular JIA subtype $29.26 \%$ (24 patients) and then oligoarticular JIA subtype 28\% (23 patients). No unclassified patients JIA were diagnosed.

Of our 82 patients, 51 (62.2\%) were females and female gender was predominant in all JIA subtypes except in ERA. Female-to-male ratio was $1.64: 1(51 / 31)$.

The range of age at onset of symptoms was between 8 months and 14.5 years and the mean age at JIA onset was $7.11 \pm 3.65$ years.

The duration of follow-up was from 6 months to 8 years; mean was $2.67 \pm 1.68$ years.

Table 3 shows main clinical features of our patients; large joints were affected in most of patients $92.68 \%(76 / 82$ patients) while small joints were affected in 36.6\% (30/82 patients).

Fever was present in all systemic onset JIA subtype and in $41.46 \%$ of the total number (34/82 patients).

Uveitis was diagnosed during the course of the disease in 7 patients $(8.53 \%)$ and in 5 patients $(21.7 \%)$ of oligoarticular JIA subtype.

Table 4 shows main laboratory investigations which were done. The most common finding at presentation was anemia in $49 / 82$ patients (59.75\%), followed by elevated ESR in $45 / 82$ patients (54.87\%) and then elevated CRP and leukocytosis in $33 / 82$ patients $(40.24 \%)$, while thrombocytosis was found in $31 / 82$ patients $(37.8 \%)$

Anemia, leukocytosis, thrombocytosis, elevated ESR, and CRP were present mostly in SoJIA.

Positive ANA was present in 30/82 patients (36.58\%) and mostly in oligoarticular JIA $12 / 23$ patients (52.17\%) and polyarticular JIA 11/24 patients (45.83\%).

Positive Rheumatoid Factor was found only in RFpositive polyarticular JIA. 
Table 5 shows the antirheumatic pharmacologic treatment received by our patients during the course of the disease. NSAIDs as the only treating agent were used in $9 / 82$ patients (10.97\%) while NSAIDs, methotrexate, systemic steroids, and biologics were received by $19 / 82$ patients $(23.17 \%)$ at different and varying length of time.

Biologic agents were given to $31 / 82$ patients (37.8\%); of these patients, 15 belonged to SoJIA. Biologic agents were mainly in decreasing order of frequency: etanercept (Enbrel), adalimumab (Humira), abatacept (Orencia), rituximab (Mabthera), and tocilizumab (Actemra).

Joint surgery, other than intra-articular corticosteroid injection, was needed in 3 patients only: one case of oligoarticular JIA, RF-negative polyarticular JIA, and RF-positive polyarticular JIA.

\section{Discussion}

This observational study was carried out in Pediatric Department at King Abdulaziz University Hospital, which is a tertiary care hospital in Jeddah, western coast of Saudi Arabia.

We aimed at this study to present the clinical features of children with JIA followed up in our center as knowing the characteristics of this disease in our community is essential to provide a better planning for medical care.

To our best of knowledge, there is only one hospital-based similar study describing the pattern of JIA in Saudi children which was published in 1997 in which arthritis classification was not according to the currently used ILAR classification system for JIA [9].

The prevalence of JIA is variable among different parts of world and different ethnic groups [2, 15]. This variability appears to include the frequency of JIA subtypes.

Unlike most of previous similar studies where oligoarticular JIA was found to be the most common, mainly in Europe, USA, Canada, South America, and Turkey [3, 16-18], the frequency of JIA subtypes in our cohort showed that systemic onset JIA was the most common subtype: 30/82 (36.5\%).

This is similar to a previous tertiary hospital-based study done in central province of Saudi Arabia which reviewed clinical features of 115 patients with JRA in which the percentage of SoJIA was found to constitute $44 \%$ of Juvenile Rheumatoid Arthritis cases [9]. In a large population-based study in Japan which included 540 children, SoJIA constituted 54\% of JIA cases [7].

Our study differs also from two studies from neighboring countries (Kuwait and Oman) in which the most predominant JIA subtype was polyarticular JIA $[11,12]$.

Polyarticular JIA was also the predominant JIA subtype in some other cohorts from South Africa, Bangladesh, and Pakistan and in a multinational study done by the Paediatric Rheumatology International Trials Organization (PRINTO) which included patients from western and eastern Europe and Latin America [4, 19-21]. ERA was found to be the predominant in other studies $[6,22]$.

Since our study was done in a tertiary center, we believe that this may affect our results as some cases of mild JIA especially oligoarticular may be treated by general pediatricians or orthopedic doctors and may not be referred to a higher center. We believe also that a single center study may not reflect the correct distribution of JIA subtypes in our country which needs multicenter- or a population-based study.

It is well known that females are generally more commonly affected than males by JIA [23] with variable gender distribution among JIA subtypes [24].

Our present data shows female predominance as 51/82 patients $(62.2 \%)$ were female. Apart from the only male child with ERA, female number was more in all JIA subtypes.

Few studies showed an overall equal or higher male-tofemale ratio $[4,6,15,25,26]$; this higher male percentage was possibly related to a higher ERA in one series [3, 25].

The mean age of onset of JIA symptoms in our patients was $7.11 \pm 3.65$ years (range: 8 months -14.5 years), which is not largely different from most studies [9, 14, 25, 27, 28]. However it is higher than the mean age in a large study which included 3167 patients from Europe and Latin America where mean age of onset of JIA symptoms was 5.8 years [21] but lower than a mean age of 9.5 years recorded in a cohort from Taiwan of 195 patients [22].

It is well known that JIA involves large joints-except hip-more often than small joints; our data showed that 92.68\% (76/82) had large joint involvement either alone or associated with small joints.

Fever in SoJIA is considered one of the diagnostic features according to ILAR criteria and it may be the main presenting symptom [9]. As reported in other studies, all our SoJIA patients had fever $[8,29-31]$.

Among all our JIA children, fever was present in 34/82 $(41.46 \%)$ patients which is higher than other similar studies $[3,29]$. which is probably due to the predominance of SoJIA in our cohort. However a higher percent (67.6\%) of fever in JRA was reported in one series [4].

Uveitis is a well-known extra-articular manifestation that affects children with JIA and it occurs more commonly in oligoarticular subtype. It may start before the onset arthritis or later during the course of the disease. Among all our JIA patients $7 / 82(8.53 \%)$ had uveitis and $5 / 23(21.7 \%)$ of oligoarticular JIA had developed uveitis. The overall rate is approximately close to what was reported in Spain [32] and Taiwan [22].

However there is significant variability in frequency of uveitis in JIA; in a series of 214 JIA children in India, only $2.2 \%$ were found to have uveitis while a rate of $29.65 \%$ was reported in another series of 172 patients [33].

Anemia in JIA is commonly caused by iron deficiency or due to chronic inflammation [34].

Anemia was the most common abnormal laboratory investigation in our patients 49/82 (59.75\%) and it was recorded in $80 \%$ of SoJIA patients. Anemia was considered as hemoglobin level less than $110 \mathrm{~g} / \mathrm{L}$ which is-according to WHO definition of anemia-a 2SD below the mean for the majority of our patients $[35,36]$.

The prevalence of anemia in our children may be increased as most of cases were SoJIA in which the anemia is more common than other JIA subtypes.

Furthermore, at presentation, it was not known if this anemia was due to JIA alone or due to other common causes 
as the frequency of anemia in children in our population was $22.3 \%$ and $30 \%$ in two local studies $[37,38]$.

However, although in other studies the cutoff point for low hemoglobin was lower, there were no major differences in the frequency of anemia $[3,10,14]$.

Being slightly higher than a local study (115 patients) and studies from UK (572 patients), Turkey (634 patients), and Taiwan (195 patients), the frequency of ANA positivity in our children was $36.58 \%[3,9,22,39]$ although higher and more lower frequencies were reported $[4,39]$.

As expected most ANA positivity cases were in oligoarticular JIA.

The aim of multidisciplinary JIA management is to control active symptoms, achieve remission, prevent joint damage, and preserve joints function to prevent disability as well as maintaining normal growth which may require early and aggressive management [40].

Pharmacologic therapy of JIA has major advances over the last two decades since the introduction of biologic agents which are being increasingly used and these agents may be used as initial therapy [41].

We usually start with NSAIDs for 4 to 6 weeks followed by DMARDs, most commonly methotrexate in case of no adequate response to NSAIDs. IAC are used to relieve joint inflammation and systemic steroids are usually used for a short time with the lowest effective dose and are tapered once we get the desired response. In case of failure of methotrexate, a trial of another DMARD or biologic therapy is introduced.

In our study, all patients were started on NSAIDs either alone or combined with other antirheumatic agents but they were the only used agent in $9 / 82$ patients (11\%).

JIA was found to be the most common indication for biologic treatment among pediatric rheumatologic conditions in a national study [42].

As shown in Table 5, 31/82 patients (37.8\%) received biologic treatment during their course of the diseases.

A major limitation of our study is being a retrospective record-based in nature and a single center-based with a relatively small sample size. However our study can be a starting point for further future nationwide multicenterbased study.

\section{Conclusion}

In our study, systemic onset JIA is the most common JIA subtype.

Although a population-based rather than a single center study will give more details about JIA characteristics in Saudi Arabia, our study can be the start point to a nationwide multicenter study.

\section{Abbreviations}

JIA: Juvenile Idiopathic Arthritis

ILAR: International League of Associations for Rheumatology

RF: Rheumatoid Factor

ANA: Anti-nuclear antibody

SoJIA: Systemic onset Juvenile Idiopathic Arthritis
ERA: $\quad$ Enthesitis-related arthritis

DMARDs: Disease-Modifying Antirheumatic Drugs

NSAIDs: Nonsteroidal anti-inflammatory drugs

MTX: Methotrexate

IAC: Intra-articular corticosteroids.

\section{Conflict of Interests}

All authors have no competing interests to declare.

\section{Authors' Contribution}

Mohammad H. Al-Hemairi and Mohammed A. Muzaffer helped in the conception and design of the study, the acquisition, analysis, or interpretation of data for the work and Shatha M. Albokhari helped in the design of the study and critically revised the paper for important intellectual content. All authors read and approved the final version of the paper. All authors agree to be accountable for all aspects of the work in ensuring that questions related to the accuracy or integrity of any part of the work are appropriately investigated and resolved.

\section{Acknowledgments}

The authors would like to thank the patients, their families, and the medical staff of Pediatric Rheumatology Clinics at King Abdulaziz University Hospital.

\section{References}

[1] R. E. Petty, T. R. Southwood, P. Manners et al., "International League of Associations for Rheumatology classification of juvenile idiopathic arthritis: second revision, Edmonton, 2001," The Journal of Rheumatology, vol. 31, no. 2, pp. 390-392, 2004.

[2] V. C. Kok, J.-T. Horng, J.-L. Huang et al., "Population-based cohort study on the risk of malignancy in East Asian children with Juvenile idiopathic arthritis," BMC Cancer, vol. 14, no. 1, pp. 634-644, 2014.

[3] E. Demirkaya, S. Özen, Y. Bilginer et al., "The distribution of juvenile idiopathic arthritis in the eastern Mediterranean: results from the registry of the Turkish paediatric rheumatology association," Clinical and Experimental Rheumatology, vol. 29, no. 1, pp. 111-116, 2011.

[4] K. Weakley, M. Esser, and C. Scott, "Juvenile idiopathic arthritis in two tertiary centres in the Western Cape, South Africa," Pediatric Rheumatology, vol. 10, no. 1, pp. 35-40, 2012.

[5] S. Naz, A. Mushtaq, S. Rehman et al., "Juvenile rheumatoid arthritis," Journal of the College of Physicians and Surgeons Pakistan, vol. 23, no. 6, pp. 409-421, 2013.

[6] V. Kunjir, A. Venugopalan, and A. Chopra, "Profile of Indian patients with juvenile onset chronic inflammatory joint disease using the ILAR classification criteria for JIA: a communitybased cohort study," The Journal of Rheumatology, vol. 37, no. 8, pp. 1756-1762, 2010.

[7] S. Fujikawa and M. Okuni, "Clinical analysis of 570 cases with juvenile rheumatoid arthritis: results of a nationwide retrospective survey in Japan," Pediatrics International, vol. 39, no. 2, pp. 245-249, 1997. 
[8] W. A. Garout and M. A. Muzaffer, "A single-center experience of systemic onset juvenile idiopathic arthritis at a tertiary hospital in Jeddah, Saudi Arabia," Open Journal of Rheumatology and Autoimmune Diseases, vol. 4, no. 4, pp. 212-218, 2014.

[9] S. Bahabri, W. Al-Sewairi, A. Al-Mazyad et al., "Juvenile rheumatoid arthritis: the Saudi experience," Annals of Saudi Medicine, vol. 17, no. 4, pp. 413-418, 1997.

[10] M. M. Moued, H. M. Al-Saggaf, H. S. Habib, and M. A. Muzaffer, "Oligoarticular juvenile idiopathic arthritis among Saudi children," Annals of Saudi Medicine, vol. 33, no. 6, pp. 529532, 2013.

[11] F. A. Khuffash, H. A. Majeed, M. M. Lubani, K. N. Najdi, S. S. Gunawardana, and R. Bushnaq, "Epidemiology of juvenile chronic arthritis and other connective tissue diseases among children in Kuwait," Annals of Tropical Paediatrics, vol. 10, no. 3, pp. 255-259, 1990.

[12] R. Abdwani, E. Abdalla, S. Al Abrawi, and I. Al-Zakwani, "Epidemiology of juvenile idiopathic arthritis in Oman," Pediatric Rheumatology, vol. 13, article 33, 2015.

[13] A. M. Abou El-Soud, A. R. El-Najjar, E. E. El-Shahawy et al., "Prevalence of juvenile idiopathic arthritis in Sharkia Governorate, Egypt: epidemiological study," Rheumatology International, vol. 33, no. 9, pp. 2315-2322, 2013.

[14] S. Salah, A. Hamshary, H. M. Lotfy, and H. Abdel Rahman, "Juvenile idiopathic arthritis, the Egyptian experience," Journal of Medical Sciences, vol. 9, no. 2, pp. 98-102, 2009.

[15] R. K. Saurenmann, J. B. Rose, P. Tyrrell et al., "Epidemiology of juvenile idiopathic arthritis in a multiethnic cohort: ethnicity as a risk factor," Arthritis \& Rheumatism, vol. 56, no. 6, pp. 19741984, 2007.

[16] C. Modesto, J. Antón, B. Rodriguez et al., "Incidence and prevalence of juvenile idiopathic arthritis in Catalonia (Spain)," Scandinavian Journal of Rheumatology, vol. 39, no. 6, pp. 472479, 2010.

[17] K. Minden, M. Niewerth, J. Listing, A. Zink, and German Study Group of Pediatric Rheumatologists, "Health care provision in pediatric rheumatology in Germany-national rheumatologic database," The Journal of Rheumatology, vol. 29, no. 3, pp. 622628, 2002.

[18] N. Adib, K. Hyrich, J. Thornton et al., "Association between duration of symptoms and severity of disease at first presentation to paediatric rheumatology: results from the Childhood Arthritis Prospective Study," Rheumatology, vol. 47, no. 7, pp. 991-995, 2008.

[19] M. I. Islam, M. K. Talukdar, and S. Rahman, "Pattern of paediatric rheumatic diseases: an experience in a tertiary care hospital, dhaka, bangladesh," Bangladesh Journal of Child Health, vol. 37, no. 2, pp. 97-101, 2013.

[20] S. Ahmed, S. R. Ali, S. Ishaque, and N. Sami, "Clinical and biochemical characteristics of children with Juvenile idiopathic Arthritis," Journal of the College of Physicians and Surgeons Pakistan, vol. 24, no. 7, pp. 498-502, 2014.

[21] R. Gutiérrez-Suárez, A. Pistorio, A. Cespedes Cruz et al., "Health-related quality of life of patients with juvenile idiopathic arthritis coming from 3 different geographic areas. The PRINTO multinational quality of life cohort study," Rheumatology, vol. 46, no. 2, pp. 314-320, 2007.

[22] C.-C. Shen, K.-W. Yeh, L.-S. Ou, T.-C. Yao, L.-C. Chen, and J.-L. Huang, "Clinical features of children with juvenile idiopathic arthritis using the ILAR classification criteria: a community-based cohort study in Taiwan," Journal of Microbiology, Immunology and Infection, vol. 46, no. 4, pp. 288-294, 2013.

[23] J. T. Cassidy and R. E. Petty, "Chronic arthritis in childhood," in Text Book of Pediatric Rheumatology, J. T. Cassidy, R. E. Petty, R. M. Laxer, and C. B. Lindsley, Eds., pp. 211-286, Saunders Elesvier, Philadelphia, Pa, USA, 6th edition, 2011.

[24] J.-L. Huang, "New advances in juvenile idiopathic arthritis," Chang Gung Medical Journal, vol. 35, no. 1, pp. 1-14, 2012.

[25] S. A. Rahman, M. I. Islam, and M. K. Talukder, "Clinical aspects of juvenile idiopathic arthritis: extended experience from Bangladesh," American Journal of Clinical and Experimental Medicine, vol. 1, no. 1, pp. 20-23, 2013.

[26] J. K. Reininga, L. I. Los, N. M. Wulffraat, and W. Armbrust, "The evaluation of uveitis in juvenile idiopathic arthritis (JLA) patients: are current ophthalmologic screening guidelines adequate?" Clinical and Experimental Rheumatology, vol. 26, no. 2, pp. 367-372, 2008.

[27] M. M. San Ildefonso and A. R. Pascual, "Juvenile idiopathic arthritis: cross-sectional study of incidence and prevalence observed in a tertiary center of spain," Pediatric Rheumatology, vol. 12, supplement 1, article P173, 2014.

[28] K. L. Hyrich, S. D. Lal, H. E. Foster et al., "Disease activity and disability in children with juvenile idiopathic arthritis one year following presentation to paediatric rheumatology. Results from the Childhood Arthritis Prospective study," Rheumatology, vol. 49, no. 1, Article ID kep352, pp. 116-122, 2010.

[29] J. Chipeta, P. Njobvu, S. Wa-Somwe, C. Chintu, P. E. McGill, and R. Bucala, "Clinical patterns of juvenile idiopathic arthritis in Zambia," Pediatric Rheumatology, vol. 11, article 33, 2013.

[30] H.-Y. Tsai, J.-H. Lee, H.-H. Yu, L.-C. Wang, Y.-H. Yang, and B.L. Chiang, "Initial manifestations and clinical course of systemic onset juvenile idiopathic arthritis: a ten-year retrospective study," Journal of the Formosan Medical Association, vol. 111, no. 10, pp. 542-549, 2012.

[31] A. Aggarwal, V. Agarwal, D. Danda, and R. Misra, "Outcome in juvenile rheumatoid arthritis in India," Indian Pediatrics, vol. 41, no. 2, pp. 180-184, 2004.

[32] J. García-Consuegra Molina, R. Tapia Moreno, J. Abelairas Gómez, J. Peralta Calvo, and R. Merino Muñoz, "Uveitis and juvenile idiopathic arthritis," Anales Espanoles de Pediatria, vol. 54, no. 3, pp. 255-259, 2001.

[33] D. Ben Ezra, C. Evelyne, and F. Behar-Cohen, "Uveitis and juvenile idiopathic arthritis: a cohort study," Clinical Ophthalmology (Auckland, NZ), vol. 1, no. 4, pp. 513-518, 2007.

[34] P. Sreenivasan and N. S. Mani, "Pure red cell aplasia in systemic onset juvenile idiopathic arthritis," Indian Journal of Hematology and Blood Transfusion, vol. 28, no. 1, pp. 42-43, 2012.

[35] J. Janus and S. K. Moerschel, "Evaluation of anemia in children," American Family Physician, vol. 81, no. 12, pp. 1462-1471, 2010.

[36] R. D. Baker, F. R. Greer, J. J. S. Bhatia et al., "Diagnosis and prevention of iron deficiency and iron-deficiency anemia in infants and young children (0-3 years of age)," Pediatrics, vol. 126, no. 5, pp. 1040-1050, 2010.

[37] A. Gad, J. Al-Quaiz, T. Khoja et al., "Anemia among primary school children (5-12 years) in Riyadh Region, Saudi Arabia: a community-based study," Canadian Journal of Clinical Nutrition, vol. 1, no. 1, pp. 27-34, 2013.

[38] A. Al-Othaimeen, A. K. Osman, and S. A. Orf, "Prevalence of nutritional anaemia among primary school girls in Riyadh 
City, Saudi Arabia," International Journal of Food Sciences and Nutrition, vol. 50, no. 4, pp. 237-243, 1999.

[39] N. Moe and M. Rygg, "Epidemiology of juvenile chronic arthritis in northern Norway: a ten-year retrospective study," Clinical and Experimental Rheumatology, vol. 16, no. 1, pp. 99101, 1998.

[40] A. Consolaro, G. Negro, S. Lanni, N. Solari, A. Martini, and A. Ravelli, "Toward a treat-to-target approach in the management of juvenile idiopathic arthritis," Clinical and Experimental Rheumatology, vol. 30, supplement 73, pp. S157-S162, 2012.

[41] S. Ringold, P. F. Weiss, T. Beukelman et al., "2013 update of the 2011 American College of Rheumatology recommendations for the treatment of juvenile idiopathic arthritis: recommendations for the medical therapy of children with systemic juvenile idiopathic arthritis and tuberculosis screening among children receiving biologic medications," Arthritis \& Rheumatism, vol. 65, no. 10, pp. 2499-2512, 2013.

[42] S. M. Al-Mayouf, A. Alenazi, and H. Aljasser, "Biologic agents therapy for Saudi children with rheumatic diseases: indications and safety," International Journal of Rheumatic Diseases, 2014. 


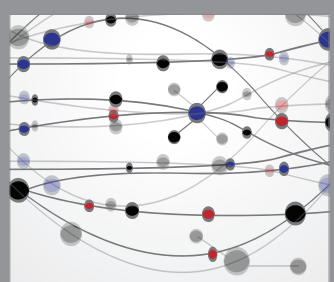

The Scientific World Journal
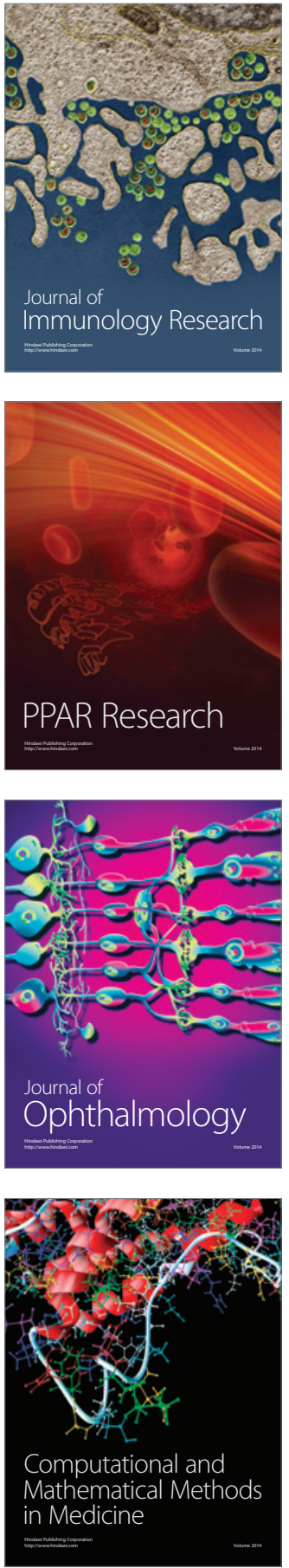

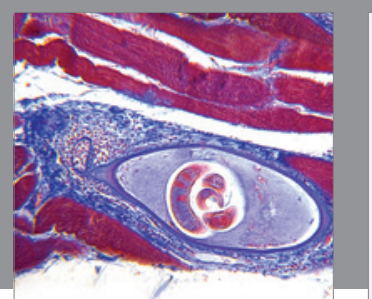

Gastroenterology Research and Practice

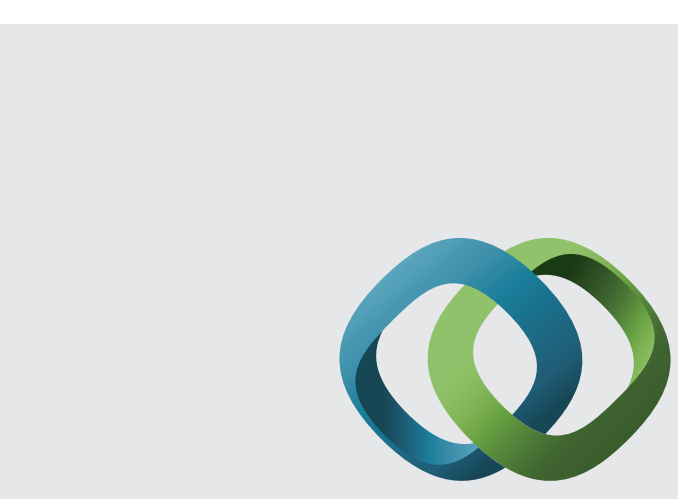

\section{Hindawi}

Submit your manuscripts at

http://www.hindawi.com
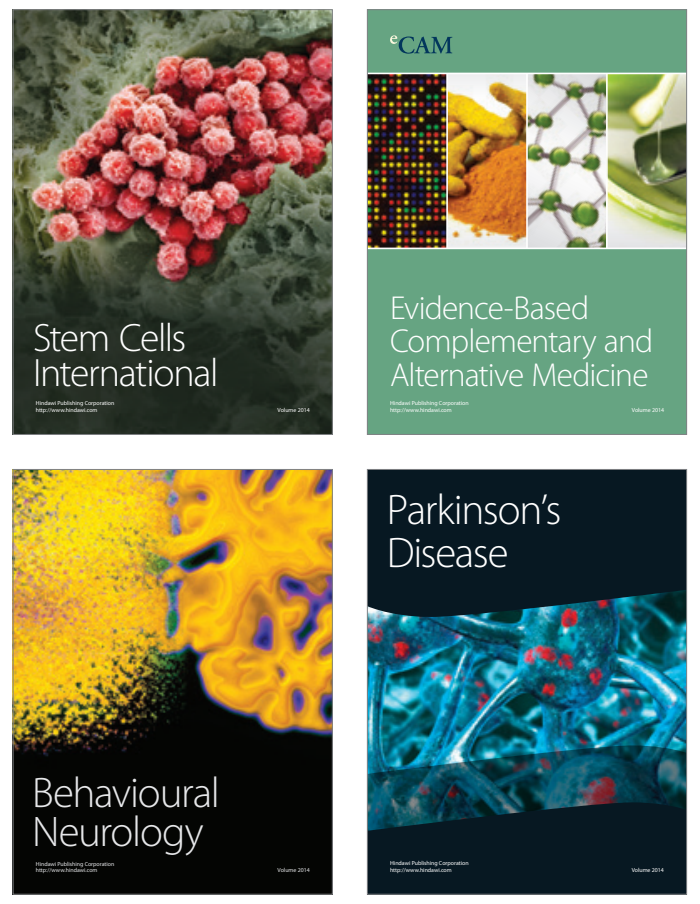
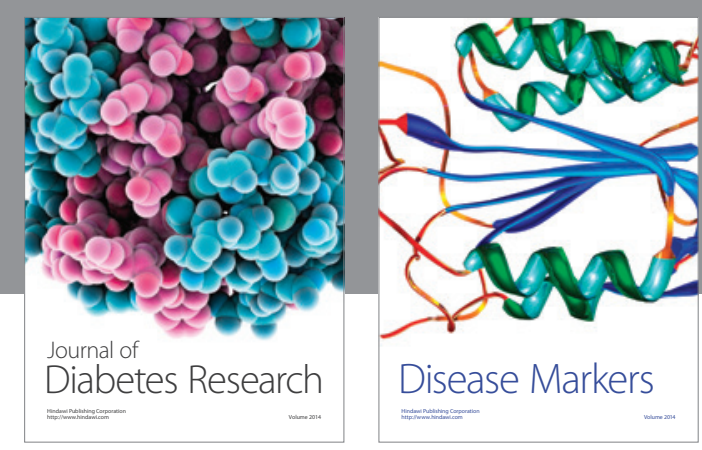

Disease Markers
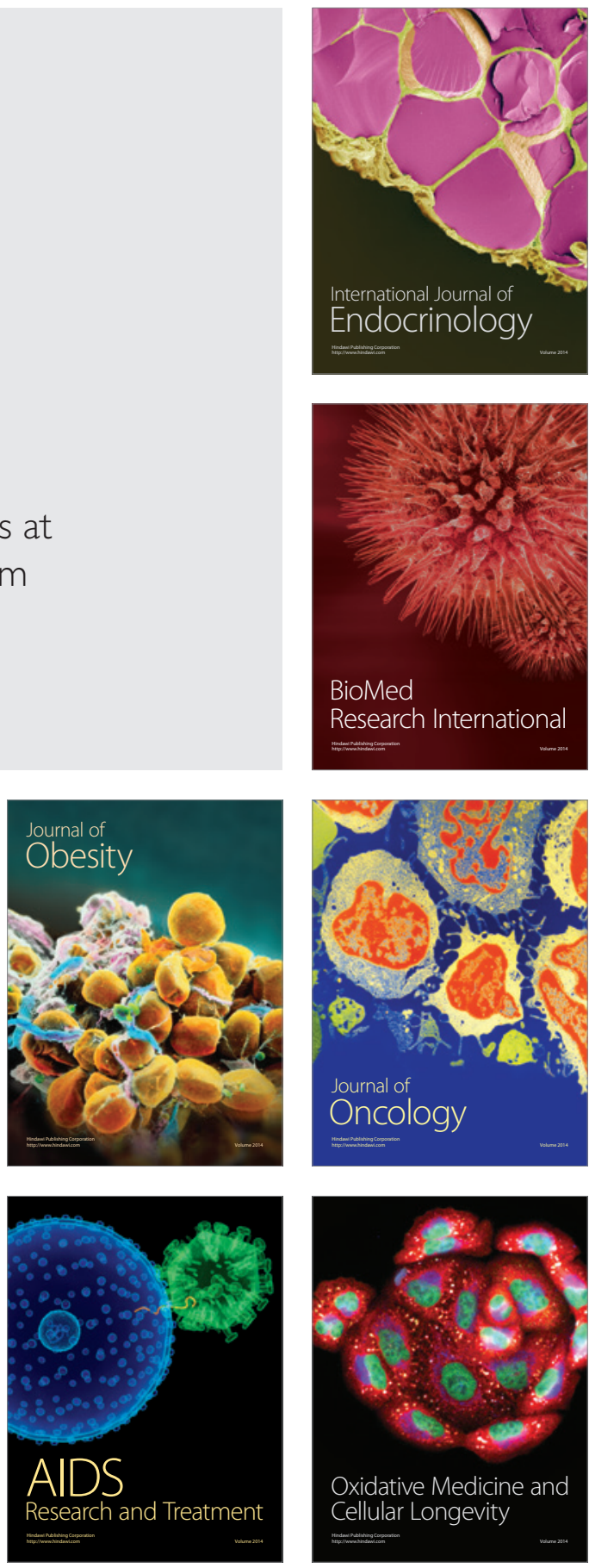